\title{
Environmental Impact Assessment of Sacrificial Anode Method in Taiwan Strait
}

\author{
Chih-Chung Wen', Han-Jen Tsai' ${ }^{1}$, Shih-Yen Hsu' ${ }^{2}$, Hsiu-Chen Yeh ${ }^{1}$ \\ ${ }^{1}$ Global Warming and Coastal Environmental Changes Research Lab., Department of Safety, Health and Environmental \\ Engineering, Hungkuang University, Taiwan \\ ${ }^{2}$ Department of Water Resources Engineering and Conservation, Feng Chia University, Taiwan \\ Email: wen1558@hk.edu.tw
}

How to cite this paper: Wen, C.-C., Tsai, H.-J., Hsu, S.-Y. and Yeh, H.-C. (2020) Environmental Impact Assessment of Sacrificial Anode Method in Taiwan Strait. Journal of Environmental Protection, 11, 622-635.

https://doi.org/10.4236/jep.2020.118037

Received: June 17, 2020

Accepted: August 11, 2020

Published: August 14, 2020

Copyright (C) 2020 by author(s) and Scientific Research Publishing Inc. This work is licensed under the Creative Commons Attribution International License (CC BY 4.0).

http://creativecommons.org/licenses/by/4.0/

\begin{abstract}
Taiwan Strait is one of the potential wind farm in the world. Cooperate with the development of national policies, thousands of offshore wind turbines will be installed in Taiwan Strait. In order to enable offshore wind turbine foundation to be erected in the ocean for a long time, the offshore structure facilities are protected by sacrificial anode or impressed current of today. This study utilized the MIKE21 numerical model, combined with ocean parameters such as sea waves and tidal current to simulate the change of the diffusion concentration and diffusion range of the materials released by the aluminum sacrificial anode blocks by the Changhua offshore wind farm located on Taiwan Strait in winter and summer, thus to evaluate the impact on the marine environment.
\end{abstract}

\section{Keywords}

Aluminum, Cathodic Protection, Sacrificial Anode, Offshore Wind Turbines, Model

\section{Introduction}

In recent years, all countries have invested heavily in the research and development of renewable energy. According to the simulation results regarding the wind energy potential in Taiwan Strait undertaken by the Industrial Technology Research Institute and commissioned by the Energy Bureau of the Ministry of Economic Affairs: at 80 meters above sea level in Taiwan Strait, the average annual wind speed is about $5-6 \mathrm{~m} / \mathrm{s}$ or more. Wind energy density can reach 750 $850 \mathrm{~W} / \mathrm{m}^{2}$, with a stable wind direction. With the gradual growth of the development of offshore wind power technology, the cost of construction is relatively 
reduced; which means, it has made renewable energy a beneficial option for protection of the marine environment. In 2012, the Ministry of Economic Affairs of the Executive Yuan approved the "thousands of sea and land and turbines" project. This promotes the national energy policy of green energy and a low carbon environment. And on July 3rd, 2015, the government published the "offshore wind power site planning operations" report announcing the potential development of 36 offshore wind turbine sites (Figure 1), thus shifting the production of wind power from the land to the ocean. Changhua Offshore Wind Farm is the largest offshore wind farm on Taiwan Strait. This paper will focus on the wind turbines built on Changhua Offshore Wind Farm to evaluate the impact on the ocean environment.

Offshore wind turbines face a harsher environment than terrestrial wind turbines. Furthermore, Taiwan is located in the subtropical region, meaning higher temperatures and humidity in comparison to offshore wind farms developed in Europe and North America. This is of particular significance to corrosion protection and monitoring of offshore wind turbines and their metal components. An offshore wind turbine is set in a highly corrosive marine environment. Its base structure is completely immersed in the seawater. Conventional corrosion prevention methods use both a cathodic protection and a coating method to enhance corrosion protection to protect the structure.

Cathodic corrosion protection is an electrochemical process applying the principles of electrochemical cells transforming a metal material into a cathode. There are two types of cathodic protection: "applied current cathodic protection" and "passive galvanic cathodic protection". The development and application of "cathode anti-corrosion" technology has been around for more than 100 years. Due to its stability, simple construction, and low maintenance cost, this

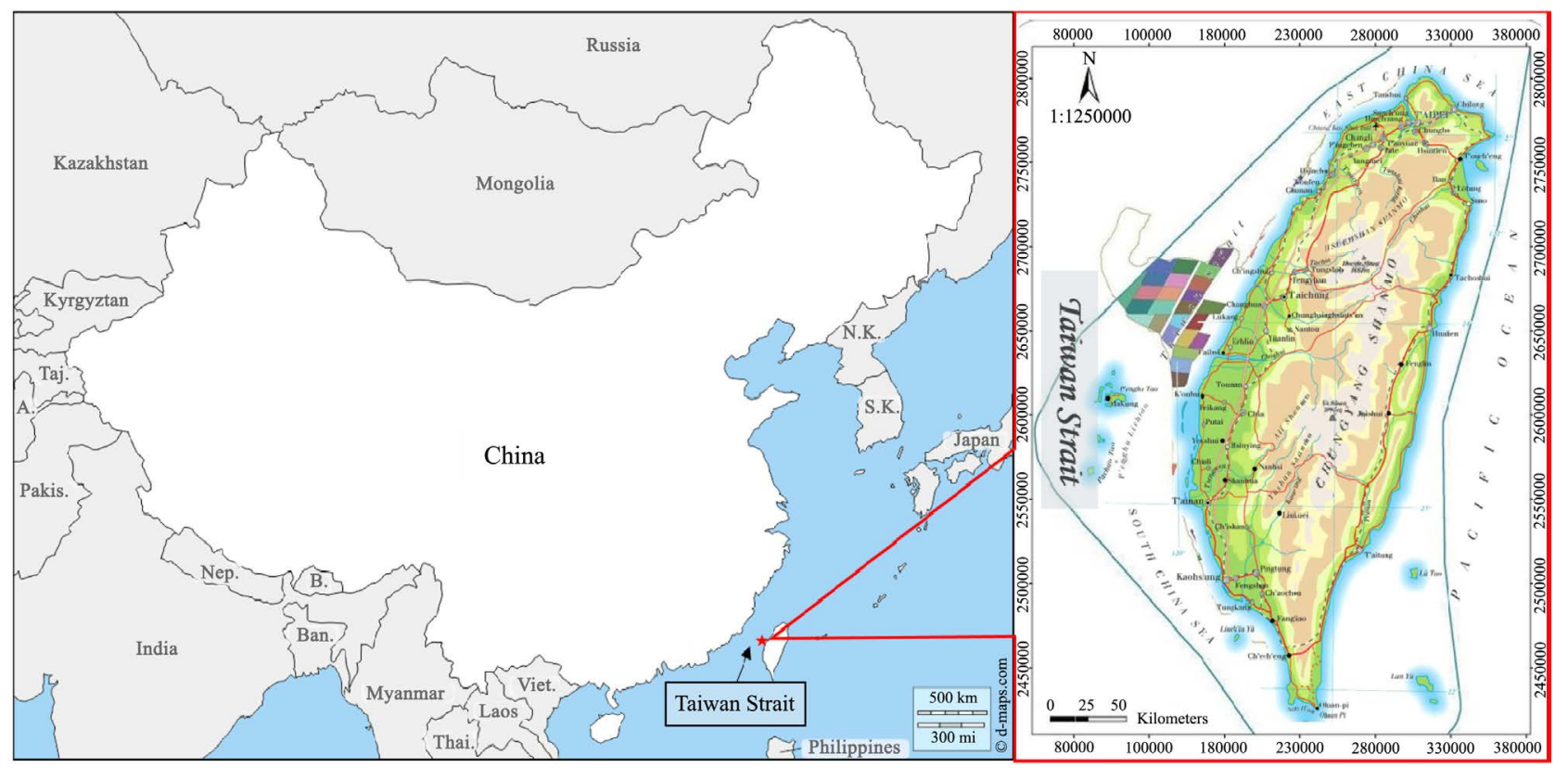

Figure 1. Offshore wind power site planning in Taiwan STRAIT [1]. 
anti-corrosion method, seen in harbor structures, is widely used in Taiwan Strait and many other countries. Combined with a coating method, it works even more effectively. In recent years, because of a few benefits, such as low density, high electricity price, and greater current generated per unit etc., an aluminum alloy (with trace amounts of zinc, mercury, indium and other elements) has replaced the commonly used metal, zinc. And it has become the main material used for "sacrificial anodes" in seawater [3]. The "sacrificial anode" process uses a highly active metal as an anode material, welded on to the surface of steel materials, to form a protection potential difference to protect against corrosion by continuously consuming the anode metal, as shown in Figure 2. The sacrificial anode metal will gradually dissolve and release into the marine environment protecting the structure against corrosion. Once the metal particles have been released, they may settle in the surrounding waters and affect the ecology [3] [4].

$\mathrm{Al}^{3+}$ ions generated by anodic dissolution may coprecipitate with calcareous deposits, and they may result in hydroxysulfate, which will possibly deposit into the final precipitate. The existence of aluminum in the acid-soluble portion of the sediment may have significant environmental influences. Hence, using aluminum sacrificial anodes in a natural environment, especially to protect the facilities near the coast, which will increase the amount of deposited metals [4]. There haven't been thorough studies or discussions about the impact of "aluminum anodes" on the environment in comparison to "zinc anodes" [5].

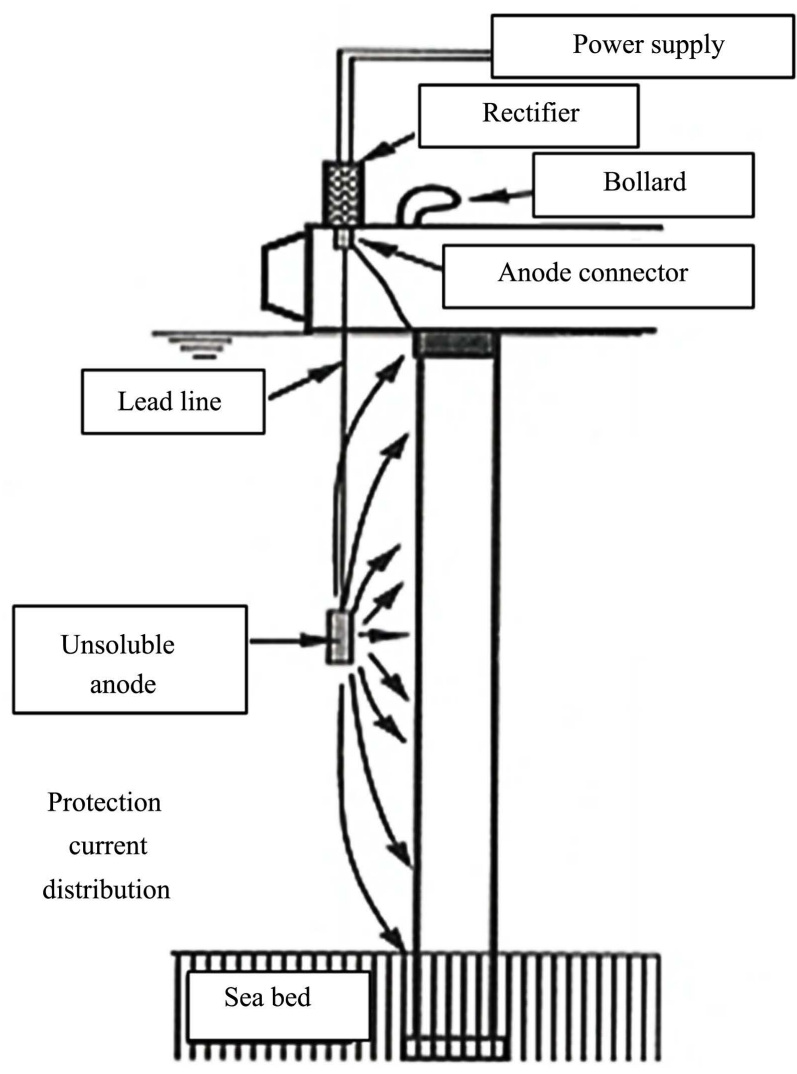

Figure 2. Cathodic corrosion protection: galvanic anode cathodic protection (GACP) [2]. 
Lately, the anti-corrosion work on marine structures has gradually been switching to aluminum sacrificial anodes. A large amount of aluminum has been released into the ocean and caused the aluminum concentration levels to rise above normal.

The existence of aluminum in the acid-soluble portion of the sediment may have significant environmental influences. Hence, we do not recommend aluminum sacrificial anodes in a natural environment, especially to protect the facilities near the coast, which will increase the amount of deposited metals.

Aluminum is a common metal mineral. It makes up about $8.1 \%$ of the earth's crust, and it is normally not defined as a pollutant. However, in most parts of the world, aluminum has severely limited the growth and existence of plant species. Since the late 70's, the research range on the toxicity of aluminum has been extended to natural habitats, including forests and aquatic areas. The toxicity of aluminum is closely connected to $\mathrm{pH}$ levels. Metal is soluble under acidic conditions $(\mathrm{pH}<5.5)$ in soil and water. It is also biodegradable. But it is relatively harmless under neutral conditions ( $\mathrm{pH} 5.5$ - 7.5) Reduction or death of invertebrates in forests and water, even the reproduction of fish and amphibians, are directly related to aluminum pollution. It also affects birds and mammals through the food chain indirectly [6].

In the aquatic environment, aluminium acts as a toxic agent on gill-breathing animals such as fish and invertebrates, by causing loss of plasma and haemolymph ions leading to osmoregulatory failure. In fish, the inorganic monomeric species of aluminium reduce the activities of gill enzymes important in the active uptake of ions. Aluminium may easily be absorbed and interfere with important metabolic processes in mammals and birds [6].

In the past decades, there have been many studies of how human activities make the aluminum concentration level higher than the natural level of coastal waters, such as coastal mining and dredging operations associated with alumina emissions, discharge and usage of acidic sulphate soils in coastal development, and aluminum used in the sacrificial anode for offshore assets protection. The aluminum concentration in an open ocean is usually $<0.7 \mu \mathrm{g} / \mathrm{L}$ [7] [8] [9] [10]. In coastal waters, it ranges from 0.1 to $16.7 \mu \mathrm{g} / \mathrm{L}$ [10]. In the heavy industrial port of Cortez in Queensland, Australia, the aluminum concentration is as high as $83 \mu \mathrm{g} / \mathrm{L}$. An important difference between the aluminum form in seawater and the aluminum form in fresh water is that there is no cation in the seawater. And it is very strong under acidic $\mathrm{pH}$ conditions. In the marine environment, aluminum is formed with mainly aluminate anion, a little bit of neutral aluminum hydroxide, and with a very small amount of colloidal aluminum. When the total concentration of aluminum is higher than $500 \mu \mathrm{g} / \mathrm{L}$, the precipitate of dissolved aluminum is mainly $\mathrm{Al}(\mathrm{OH})_{3}$ with a small amount of hydrated aluminum magnesium carbonate. When performing toxicity tests of bioavailability, the types of aluminum will vary with $\mathrm{pH}$ levels, time and concentration. Thus, the toxicity of the element is directly related to the metal form [11].

This study intends to use the MIKE21 model to simulate the change in the 
timespace flow field under the different seasons in the Changhua offshore wind power planning site.

With the application if the marine physical numeral model, MIKE21_HD, combined with ECO LAB ecological mode, to estimate the simulated distribution and concentration in Taiwan Strait after the sacrificial anode metal (aluminum) is dissolved when using this method of corrosion protection in the area (Figure 3).

\section{Study Methods}

This study uses both the MIKE21 (Hydro Dynamic, HD) and water quality ecological heavy metal modules to research the hydrodynamics of the Taiwan Strait to explore the changes in the time space flow field under the influence of tides. MIKE 21 Flow Model is a modelling system for 2D free-surface flows. MIKE 21 Flow Model is applicable to the simulation of hydraulic and environmental phenomena in lakes, estuaries, bays, coastal areas and seas. It may be applied wherever stratification can be neglected. The hydrodynamic (HD) module is the basic module in the MIKE 21 Flow Model. It provides the hydrodynamic basis for the computations performed in the Environmental Hydraulics modules. The hydrodynamic module simulates water level variations and flows in response to a variety of forcing functions in lakes, estuaries and coastal regions. MIKE ECO Lab gives easy access to the formulation of the biological, chemical and settling processes. The user has the option of viewing, modifying, or creating the formulation of the processes and to introduce new state variables to simulate. It is therefore possible to create completely new model concepts containing the necessary causal relations to describe the specific phenomena in question.

The complete simulation application process is shown in Figure 4. The grid layout of the hydrodynamic local area calculation is shown in Figure 5, and calculation conditions are shown in the following paragraphs. During calculation, the effect of the radiation stress generated by the wind and waves on the water flow is added. Having three sides of each area that border the ocean is also considered in calculations using the DHI Toolbox to calculate the corresponding tidal water levels (Table 1).

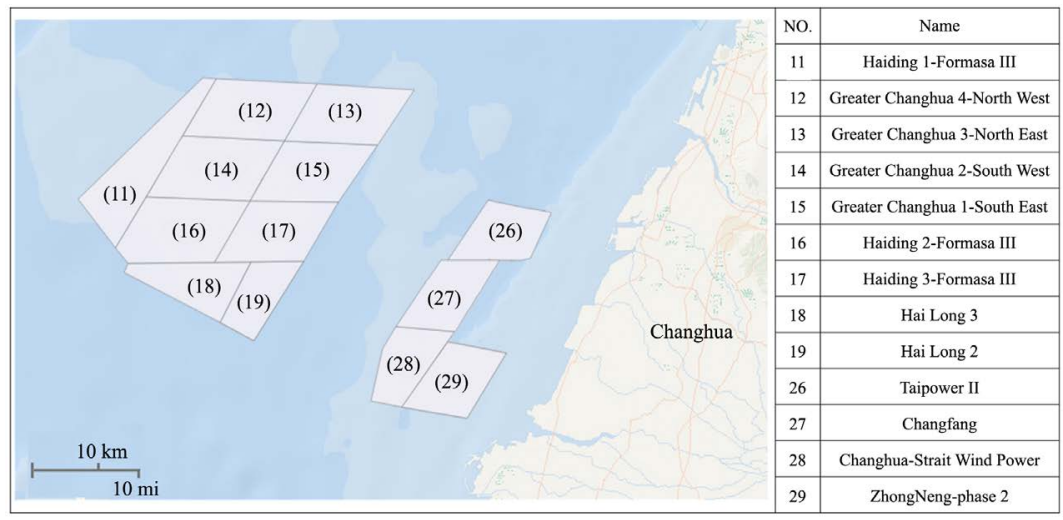

Figure 3. Offshore wind farms in Changhua sea area. 
Table 1. Simulation setting.

\begin{tabular}{|c|c|}
\hline \multicolumn{2}{|l|}{ HD MODEL } \\
\hline CFL-MAX.: & 0.8 \\
\hline Flood and dry: & Yes \\
\hline Eddy viscosity: & Smagorinsky formulation $(0.28)$ \\
\hline Bed resistance: & Manning number (32) \\
\hline Coriolis: & Yes \\
\hline Wind forcing: & Vary in time \\
\hline Radiation stress: & $\begin{array}{l}\text { Vary in time and domain } \\
\text { (From SW model) }\end{array}$ \\
\hline Boundary conditions: & All tidal elevation \\
\hline Temperature salinity module: & Yes (constant) \\
\hline CFL-MAX.: & $(0.8)$ \\
\hline \multicolumn{2}{|c|}{ Hearty Metal MODEL } \\
\hline Organic-carbon partitioning coefficient: & $50,000(1 / \mathrm{kg})$ \\
\hline Desorption rate in water: & 1 (/day) \\
\hline Desorption rate in sediment: & 0.1 (/day) \\
\hline Fraction of organic carbon in suspended solids SS: & 0.1 (dimensionless) \\
\hline Fraction of organic carbon in sediment: & 0.2 (dimensionless) \\
\hline Thickness of water film: & $0.1(\mathrm{~mm})$ \\
\hline $\begin{array}{l}\text { Ratio between thickness of diffusion } \\
\text { layer in sediment and sediment thickness: }\end{array}$ & 0.5 (dimensionless) \\
\hline Factor for diffusion due to bioturbation etc.: & (dimensionless) \\
\hline Moleweight of heavy metal: & $78.01(\mathrm{~g} / \mathrm{mole})$ \\
\hline ECO Lab time step: & Built-in \\
\hline Density of dry sediment: & $2650\left(\mathrm{~kg} / \mathrm{m}^{3}\right.$ bulk $)$ \\
\hline Porosity of sediment: & $0.4\left(\mathrm{~m}^{3} \mathrm{H}_{2} \mathrm{O} / \mathrm{m}^{3}\right.$ bulk $)$ \\
\hline Settling velocity of SS: & $1-100$ (m/day) \\
\hline Resuspension rate: & $1000\left(\mathrm{gDW} / \mathrm{m}^{2} /\right.$ day $)$ \\
\hline Particle production rate: & $1\left(\mathrm{gDW} / \mathrm{m}^{2} /\right.$ day $)$ \\
\hline Critical current velocity for sediment resuspension: & $1(\mathrm{~m} / \mathrm{s})$ \\
\hline
\end{tabular}

\begin{tabular}{cc}
\multicolumn{2}{c}{ Wave Conditions } \\
\hline Boundary conditions: & Summer, Winter \\
Wave height $(\mathrm{m}):$ & $1.2,2$ \\
Period (second): & $6.5,8$ \\
Wave direction: & $225,22.5$ \\
\hline
\end{tabular}




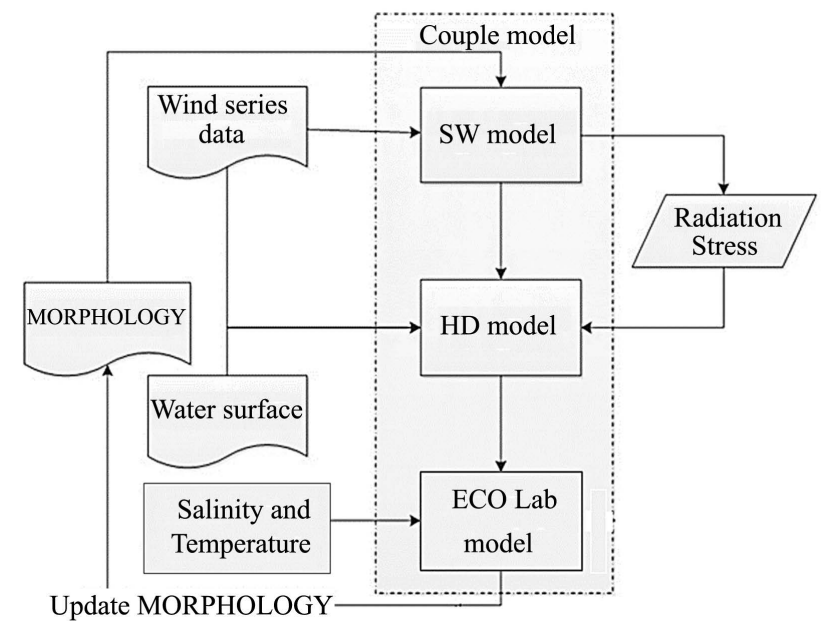

Figure 4. Flow chart of MIKE21 coupled model.

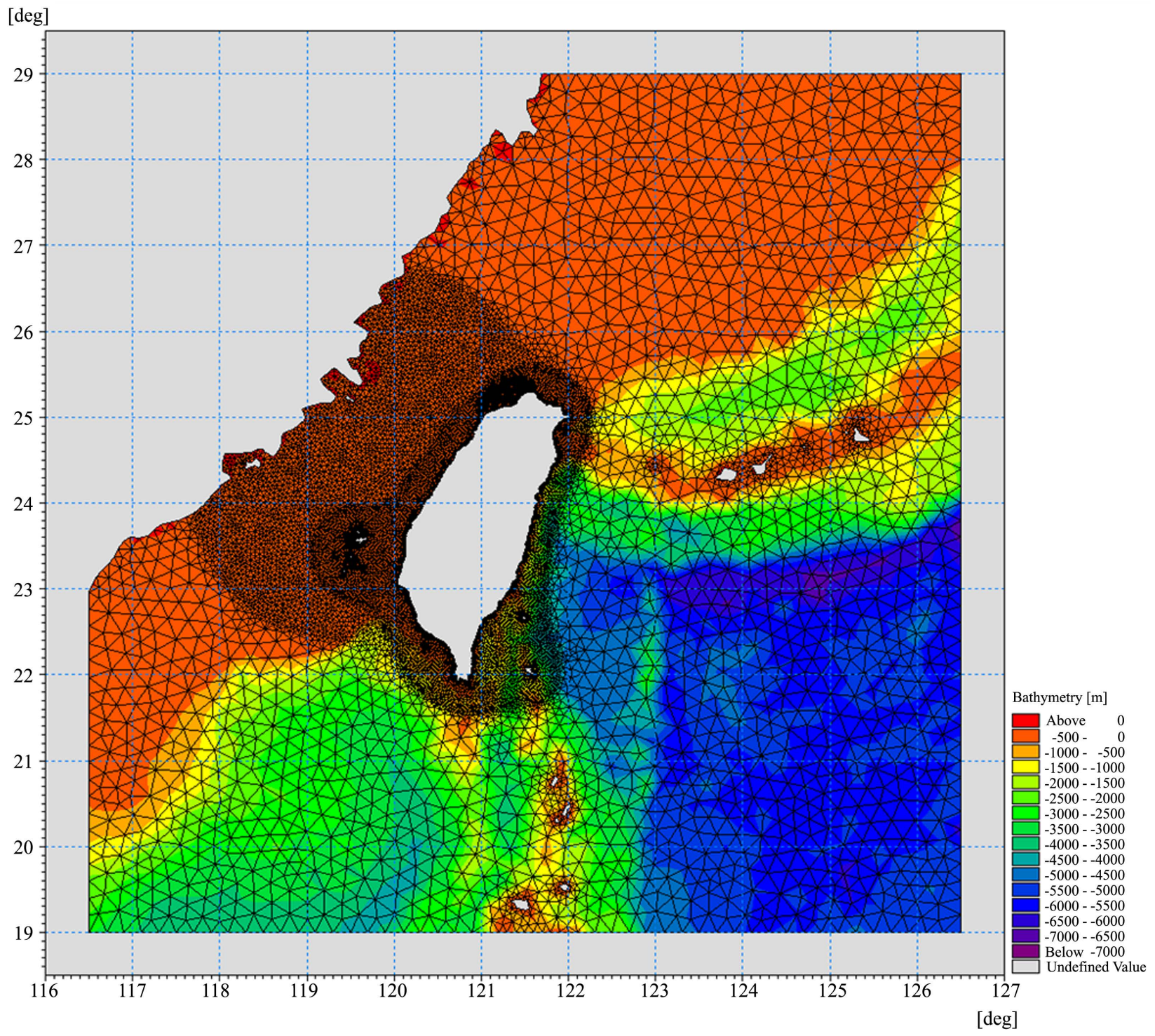

Figure 5. Model grid of study area. 


\section{Model Verification}

In order to obtain high-precision simulation results in the project area, this study specifically uses a dense grid for calculation in the western sea area in Taiwan Strait. To confirm the accuracy of the sea area flow field setting and related calculation results, the measured data of Taichung port is selected as the reference for verifying the simulation results. After verifying the simulation calculation of tidal level, flow rate and flow direction with the actual measured data the comparison results are detailed in Figure 6. The hollow point in the figure is the actual measured data, and the solid line is the simulated result. As seen from the figure, the actual tidal level of Taichung port and the simulated level are highly consistent with each other.

According to the data collection of the Changhua offshore wind farm environmental impact assessment report, the total area of the wind farm is about $2260 \mathrm{~km}^{2}$; the average water depth is about $28-45 \mathrm{~m}$; and the site is scattered 5 $50 \mathrm{~km}$ away from shore. In this area, there are a total of 1022 offshore wind turbine foundation piles and they are distributed as shown in Figure 7.
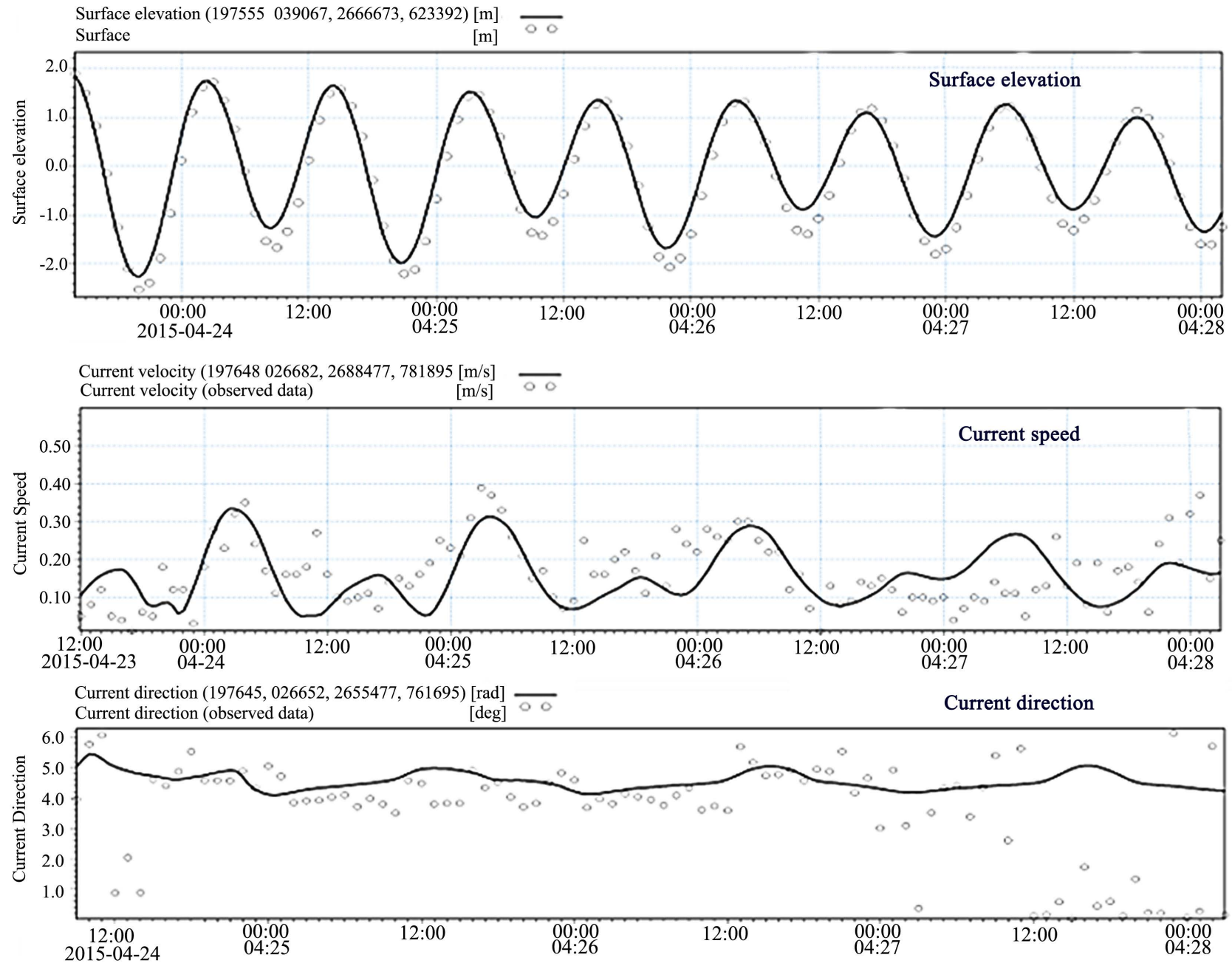

Figure 6. Taichung harbor calibration. 


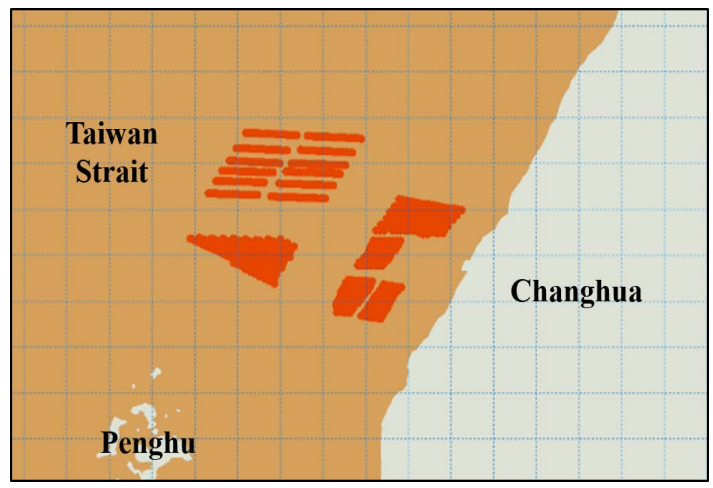

Figure 7. Offshore wind turbines set up in Changhua sea area.

\section{Results and Discussion}

In order to explore the motion characteristics of the aluminum anode after release from the offshore wind turbines in Changhua, this research took considerations in wind turbine foundation setup plans with tidal actions as the main power source. Furthermore, by using a 25 -year corrosion prevention plan including a consumption of 25-ton aluminum alloy metal as an initial simulation condition, the study calculated the dissolution and sedimentation of sea water with different season conditions.

\subsection{Flow Field}

In order to know the influence of windlessness, tidal current field is affected by topography, it is necessary to carry out the flow field calculation of large area, use the large area topographic depth, and use the output result of DHI MIKE21 global tide forecast system as a boundary condition, and the distribution of flow field in Taiwan Strait is shown in Figure 8 and Figure 9. The color scale in the figure represents the calculation of the sea level line, arrow saline indicates the size and direction of the current seamount in the sea area, the tide is flowing from the north and south ends of the Taiwan Strait to the middle sea area, and the tide is flowing from the mid-water area to the north and south ends of the Strait.

\subsection{Winter}

Figure 10 shows the wave field of the planning area affected by wave during winter, from the figure, wave shows in north incident during winter, near shore wave height was about $1.2 \mathrm{~m}$. Figure shows the flow field in the planning area was mainly affected by tidal reciprocation, flow from southwest to northeast during high tide, northeast to southwest during low tide. Figure 11 shows aluminium concentration distribution in the planning area which affected by wave during winter, from the figure, due to the effect of tidal reciprocation, dissolved aluminium mainly concentrated in Changhua and Yunlin outer sea, small amount distributed at Taichung northern side, overall released highest concentration was about $0.018 \mathrm{mg} / \mathrm{L}$. 


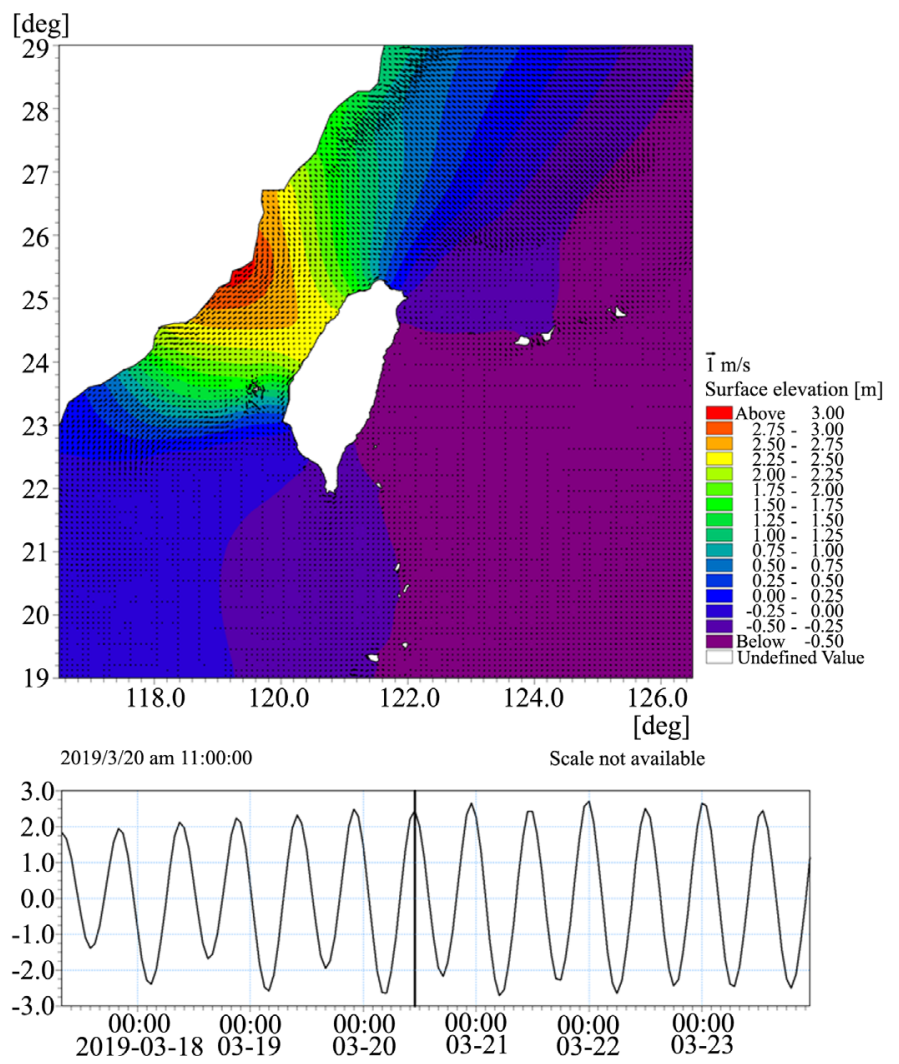

Figure 8. Flow field distribution in high tide.

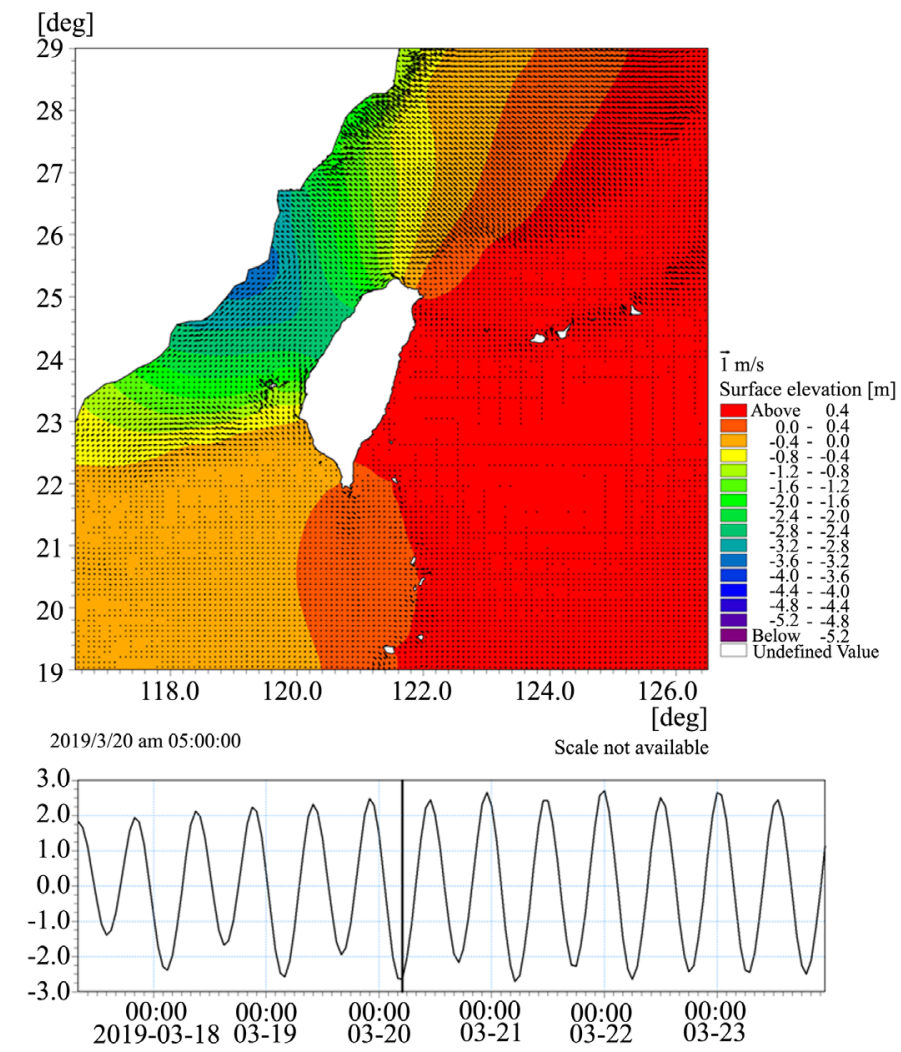

Figure 9. Flow field distribution in low tide. 


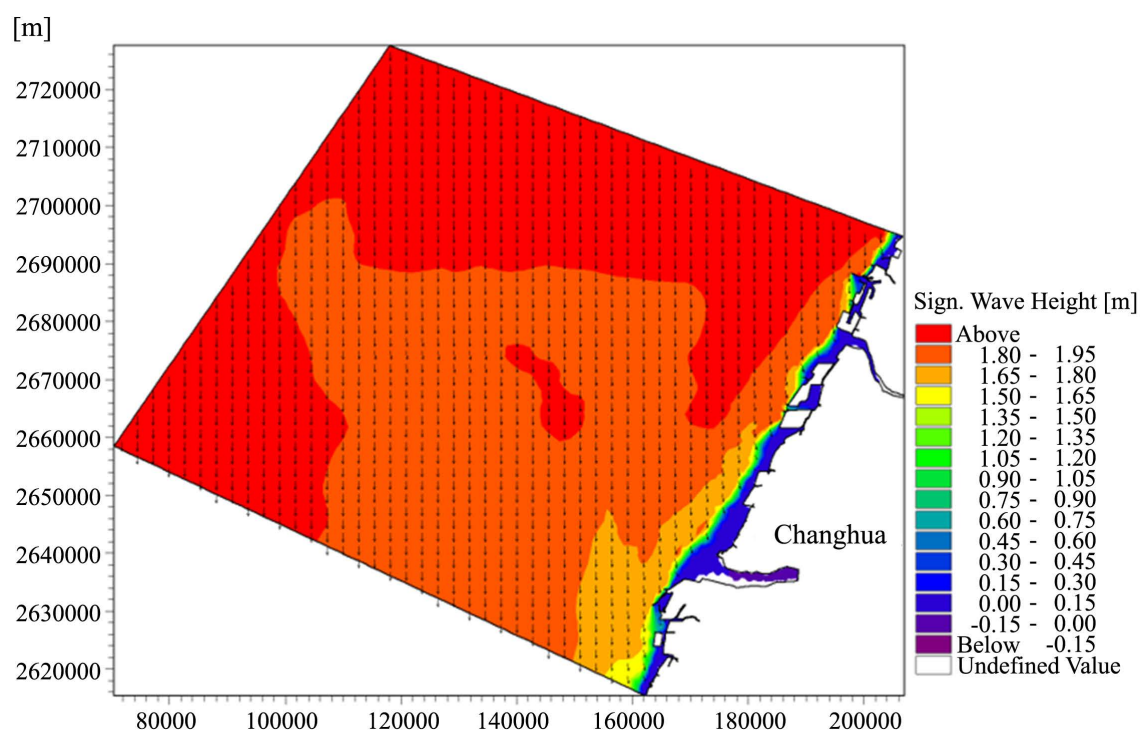

Figure 10. Wave simulation in winter.

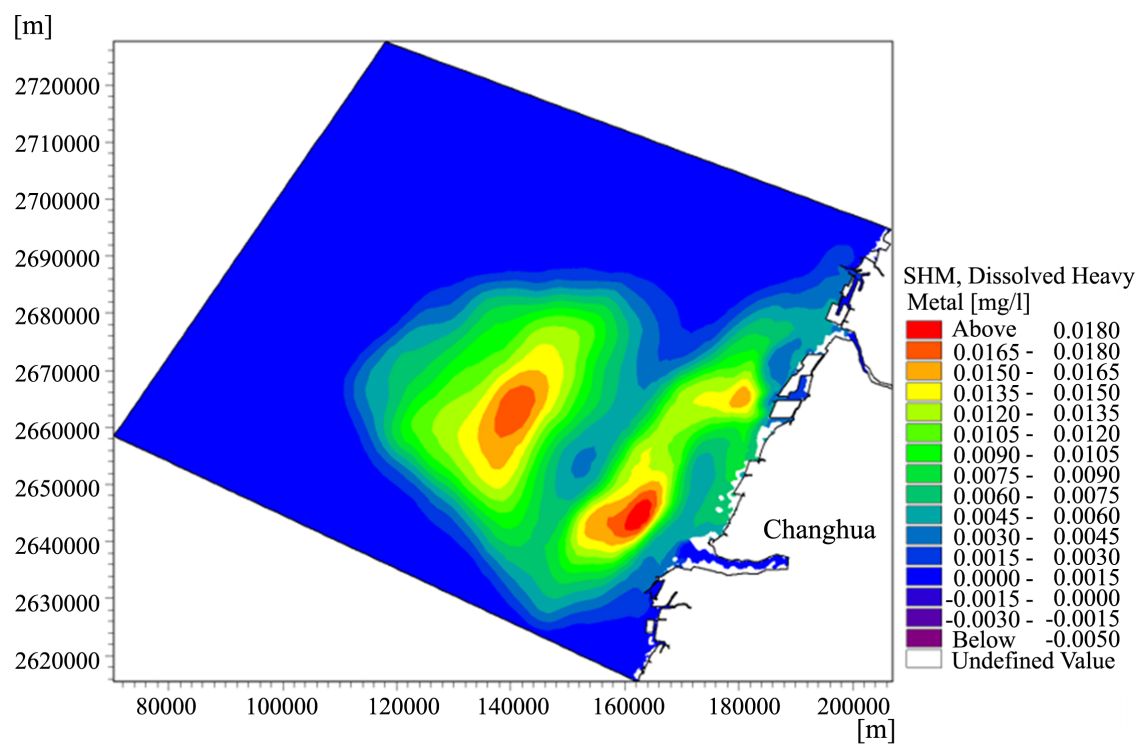

Figure 11. Aluminium diffusion simulation in winter.

\subsection{Summer}

Figure 12 shows the wave field diagram of planning area affected by wave during summer, from the figure, wave shows in southwest incident during summer, near shore wave height was about $0.8 \mathrm{~m}$. From the figure, the flow field in the planning area was mainly affected by tidal reciprocation, flow from southwest to northeast during high tide, northeast to southwest during low tide. Figure 13 shows aluminium concentration distribution in the planning area which affected by wave during summer, from the figure, due to the effect of tidal reciprocation, dissolved aluminium mainly concentrated in Changhua and Yunlin outer sea, less affected against surrounding sea area, overall released highest concentration was about $0.018 \mathrm{mg} / \mathrm{L}$. 


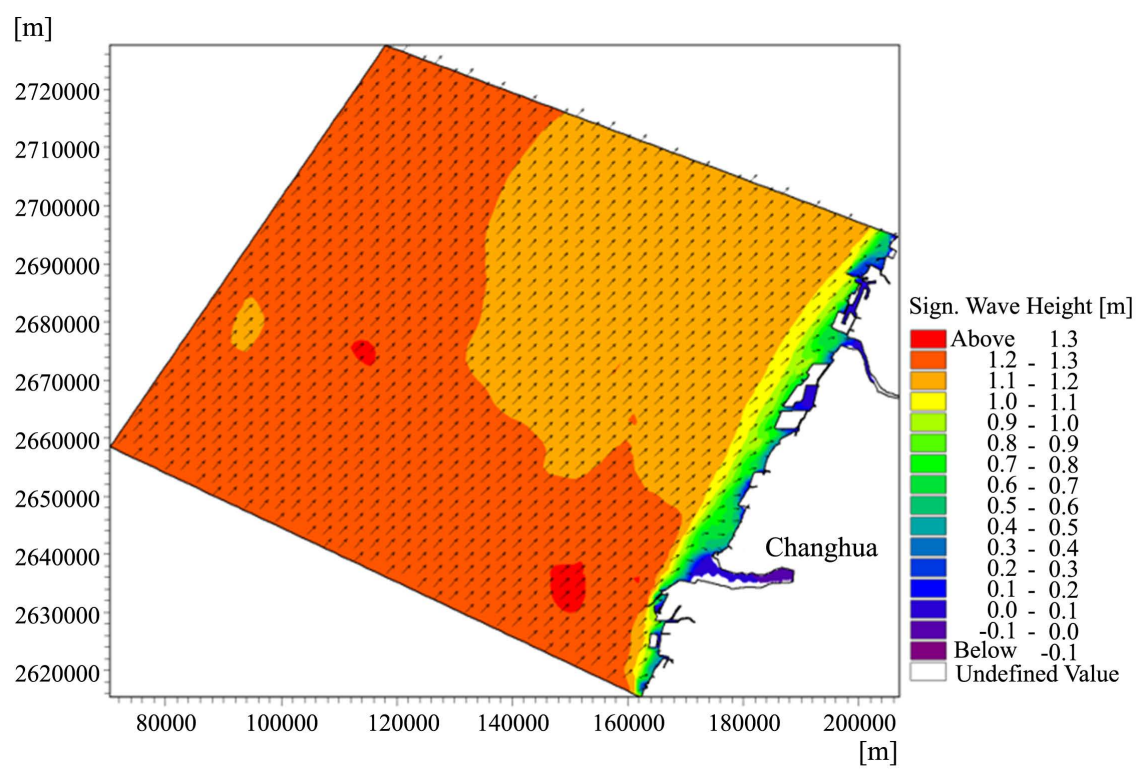

Figure 12. Wave field distribution in summer.

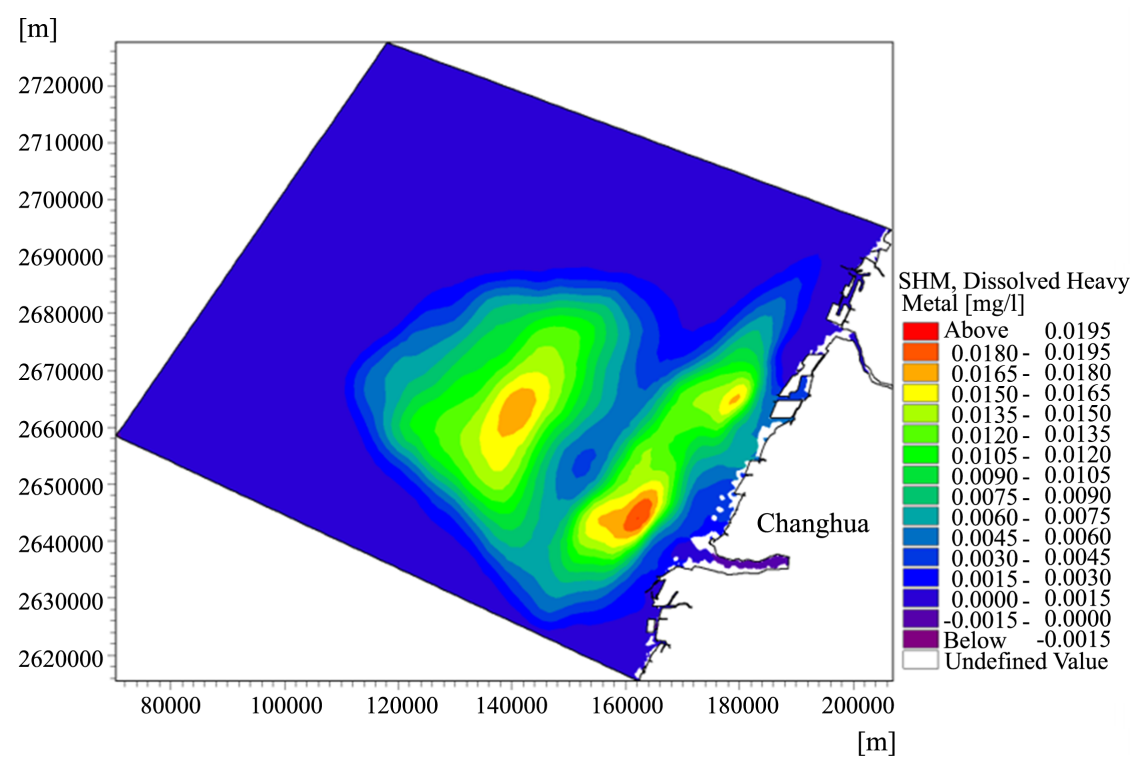

Figure 13. Aluminium diffusion simulation in summer.

\subsection{Conclusions and Suggestions}

This study uses the MIKE21 model to consider the setup plan for offshore wind turbines in Changhua, using tidal actions as the main power source, to estimate the diffusion concentration and diffusion range in aluminum sacrificial anode block.

The results of the concentration distribution in winter and summer are similar, which shows that under the condition of seasonal waves, the chemical is affected by the current greatly. Besides, the foundation is located on Changhua offshore, so it is affected by the tidal current, not the coastal current; therefore the concentration and distribution of winter are similar in winter and summer. 
According to the aforementioned reference, animals and plants contaminated with aluminum may be a key hub for aluminum entering the terrestrial food chain. We should conduct long-term monitoring in order to more accurately assess the harm caused by aluminum.

The marine dynamics of this study only uses tidal actions as its sole source. There are still other factors to be considered, i.e. the impact of nearshore flow field and seasonal effects. In terms of actual location observation, currently there are no wind turbine foundation pile erections in the Changhua sea area. So there is no field survey data. In order to have a more accurate grasp of the sedimentation concentration and the diffusion range, it is necessary to gather more related information from field surveys. The impact of the corrosion resistance of turbine piles and the movement rate of the sediments on the surrounding environment also need careful assessment after the setup of the offshore wind turbines in Changhua.

\section{Conflicts of Interest}

The authors declare no conflicts of interest regarding the publication of this paper.

\section{References}

[1] Bureau of Energy (2015) Essential of Application for Offshore Wind Farm Operations. Bureau of Energy, Ministry of Economic Affairs, Taiwan.

[2] Luo, J.S. and Jao, C. (2007) Corrosion and Cathodic Protection of Infrastructures in Taiwan. Journal of Chinese Corrosion Engineering, 21, 1-20.

[3] Shibli, S.M.A., Archana, S.R.P. and Muhamed, A. (2008) Development of Nano Cerium Oxide Incorporated Aluminium Alloy Sacrificial Anode for Marine Applications. Corrosion Science, 50, 2232-2238. https://doi.org/10.1016/j.corsci.2008.06.017

[4] Leleyter, L., Baraud, F., Reinert, T., Gouali, S., Lemoine, M. and Gil, O. (2018) Fate of Aluminium Released by Sacrificial Anodes-Contamination of Marine Sediments by Environmentally Available Compounds. Comptes Rendus Geoscience, 350, 195-201. https://doi.org/10.1016/j.crte.2018.05.003

[5] Caplat, C., Oral, R., MahautMao, M.L., Barillier, A.D., Guida, M., Rocca, C.D. and Pagano, G. (2010) Comparative Toxicities of Aluminum and Zinc From Sacrificial Anodes or from Sulfate Salt in Sea Urchin Embryos and Sperm. Ecotoxicology and Environmental Safety, 73, 1138-1143. https://doi.org/10.1016/j.ecoenv.2010.06.024

[6] Rosseland, B.O., Eldhuset, T.D. and Staurnes, M. (1990) Environmental Effects of Aluminium. Environmental Geochemistry and Health, 12, 17-27. https://doi.org/10.1007/BF01734045

[7] Kramer, J., Laan, P., Sarthou, G., Timmermans, K.R. and de Baar, H.J.W. (2004) Distribution of Dissolved Aluminium in the High Atmospheric Input Region of the Subtropical Waters of the North Atlantic Ocean. Marine Chemistry, 88, 85-101. https://doi.org/10.1016/j.marchem.2004.03.009

[8] Measures, C.I., Brown, M.T. and Vink, S. (2005) Dust Deposition to the Surface Waters of the Western and Central North Pacific Inferred from Surface Water Dissolved Aluminum Concentrations. Geochemistry, Geophysics, Geosystems, 6. https://doi.org/10.1029/2005GC000922 
[9] Middag, R., van Slooten, C., de Baar, H.J.W. and Laan, P. (2011) Dissolved Aluminium in the Southern Ocean. Deep Sea Research Part II: Topical Studies in Oceanography, 58, 2647-2660. https://doi.org/10.1016/j.dsr2.2011.03.001

[10] Angel, B.M., Apte, S.C., Batley, G.E. and Golding, L.A. (2015) Geochemical Controls on Aluminium Concentrations in Coastal Waters. Environmental Chemistry, 13, 111-118. https://doi.org/10.1071/EN15029

[11] Gillmore, M.L., Golding, L.A., Angel, B.M., Adams, M.S. and Jolley, D.F. (2016) Toxicity of Dissolved and Precipitated Aluminium to Marine Diatoms. Aquatic Toxicology, 174, 82-91. https://doi.org/10.1016/j.aquatox.2016.02.004 